\title{
Analysis on Management of Job Burnout of Counselors in Chinese Colleges Based on Game Theory
}

\author{
https://doi.org/10.3991/ijet.v15i17.16739 \\ Xiaolei Wang, Ruoxuan Zhang \\ University at Qinhuangdao, Qinhuangdao, China \\ Zengxin $\mathrm{Li}\left({ }^{\square}\right)$ \\ Qinhuangdao Vocational and Technical College, Qinhuangdao, China \\ leezengxin@126.com \\ Junlong Chen \\ Northeastern University at Qinhuangdao, Qinhuangdao, China
}

\begin{abstract}
In Chinese colleges, counselors need to simultaneously engage in teaching and management. The dual responsibilities make them probe to job burnout. To solve the problem, this paper puts forward assumptions about the behavior, income, and cost of counselors, and sets up a game model of burnout governance for college counselors. On this basis, the game between the college and counselors was analyzed under multiple scenarios: the two parties make completely independent decisions; the college is the first mover in the decisionmaking- namely the equilibrium of the mixed strategy. Suppose a few colleges decide to improve the counselor management system. Based on the evolutionary game model, the authors discussed the influence of the improvement on all the colleges. The results show that the rational choices of the two parties should be "the college reforms the counselor management system", while "the counselors work actively and avoid job burnout"; if a few colleges decide to improve the counselor management system, all the other colleges will follow suit, which leads to an improvement of efficient incentive system for college counselors. The research results provide a good reference for the burnout governance of college counselors.
\end{abstract}

Keywords_-College counselor; job burnout; game theory; governance.

\section{Introduction}

Job burnout refers to the state of physical and mental fatigue and exhaustion of individuals under heavy work pressure. Freudenberger [1] proposed that burnout is a negative symptom that appears in the helping profession. Maslac et al. [2] believe that job burnout is specifically manifested in three dimensions: exhaustion, negative attitude towards work (cynicism), and reduced professional efficacy, i.e., when the service provides performs emotional output, their ability to respond to the service receiver is exhausted, resulting in frustration and depression, gradually changes to a cynical 
(depersonalized) work attitude [3], and leads to a long-term reduction in personal professional efficacy. Job burnout will bring negative effects to individuals and groups, causing a significant reduction in work efficiency. It contagiously passes on in the informal interaction of group work and has a negative "spillover" effect on individual family life [4]. Specific effects include emotional burden, cognitive rigidity, interpersonal ridicule [5], irritability, depression, anxiety, fatigue and insomnia, decreased self-esteem, and so on.

In recent years, the problem of job burnout among college counselors in China is more prominent, which seriously affects their work efficiency. The special professional nature of the counselors makes them prone to a decline in mental health under high-intensity work, and then the job burnout. There are also certain institutional reasons for the job burnout of counselors: First, the volume of higher education has generally increased worldwide, and higher education has developed from elitist to popularization [6]. With the scale of Chinese college students expanding rapidly, work intensity and pressure of counselors have increased sharply. Secondly, the change in demands for social talent structure has accelerated. To adapt to the needs of diversified talents, lots of changes have occurred in the training system, while the work of counselors has also become more complicated, and their personal quality requirements have also increased significantly. Third, the professional position of counselors and professional teachers is different greatly, and the existing promotion methods of colleges are not suitable for counselors. Under the incomplete management system of counselors, a relatively independent stakeholder has formed between colleges and counselors. Both parties are inconsistent in interests: the counselors aim to obtain higher treatment and training development opportunities, while colleges prefer to consider the overall development strategy and cost. The balancing process of the two parties determines the development trend of the counselor's job burnout phenomenon.

Using game theory as an analytical tool, this paper establishes a game model of job burnout for college counselors. On this basis, it analyzes the internal logic of the relationship between counselors and colleges and further discusses effective ways to manage college counselors' job burnout.

\section{$2 \quad$ Model Building}

This paper proposes the following assumptions about the behavior of the counselor's job burnout. On this basis, it explores the logical mechanism of the counselor's job burnout formation and governance.

\subsection{Counselor's behavioral assumptions}

Counselors are completely rational people, and they can act to maximize net income through profit and loss comparison. Profit and loss refer to the difference between the counselor's benefits and costs. The combination of actions that maximize the overall profit and loss is the optimal choice for the counselor's behavior. 


\subsection{Counselor's cost assumption}

The counselor's cost is assumed to be the cost paid for the work, including the objective cost, potential cost, and future cost of the counselor.

Among them, the objective cost includes the time cost, workload, and selfimprovement cost; under the premise of obtaining the same self-improvement, the self-improvement awareness of the counselor is positively correlated with the selfimprovement efficiency, but negatively correlated with the actual self-improvement cost paid by the counselor. Potential costs include the costs of labor and mentality when the counselor's self-planning is vague. When the counselor is in a period of job burnout and confusion, the efficiency of the work will be reduced to a certain extent, and there will be purposeless and repetitive labor conditions. Meanwhile, the counselor needs to deal with the sudden situation of the students, causing them in a state of emotional tension for a long time, and affecting their work efficiency. The future cost means the counselor's exploration cost. With an unclear career plan, the counselor needs to spend more time and cost in analyzing and exploring their job goals.

Therefore, the cost of the counselor's work is expressed as:

$$
\begin{gathered}
G=\beta_{1} g_{1}+\beta_{2} g_{2}+\beta_{3} g_{3}=\beta_{1}(s t+z-l)+\beta_{2}\left(h_{2}+\right)+\beta_{3} h_{2} \\
\beta_{1}, \beta_{2}, \beta_{3}>0, \beta_{1}+\beta_{2}+\beta_{3}=1,0<s, t, z, l, h, c<1, l<z
\end{gathered}
$$

where, $G$ is the total cost of the counselor, $g_{1}$ is the objective cost, $g_{2}$ is the potential cost, and $g_{3}$ is the future cost; $s$ is the time cost, $t$ is the objective unit workload, $z c$ is the objective self-improvement cost, and $l$ is the counselor's self-improvement awareness; $h_{2}$ is the personal career planning cost, and $c$ is the possibility of a sudden situation during the counselor's work. To distinguish the effect of the three types of costs on the total cost of the counselor, $g_{1}, g_{2}, g_{3}$ were each given a weight $\beta_{1}, \beta_{2}, \beta_{3}$, enabling the sum of the weights $\beta_{1}, \beta_{2}, \beta_{3}$ to be 1 . Under the premise of the consistent objective workloads, the stronger the counselor's self-improvement awareness, career planning level, and work mentality, the higher the counselor's work efficiency and the lower the cost.

\subsection{Counselor's income assumption}

The counselor's income refers to the personal income brought by the work, including the objective income, potential income, and future income.

Among them, objective income includes the salary income and sense of career achievement. The higher salary income and external recognition can enhance career achievement and motivation of the counselors, and improve the work efficiency and work quality. Potential benefits include the ability enhancement made by the work of the counselors. Their ability enhancement depends on their own development consciousness, career planning, the degree of importance attached to counselors by colleges, and the allocation ratio of promotion opportunities. Future income refers to the future development space of the counselor, which depends on the impact of the current workload and ability enhancement on future career development. 
Therefore, the income obtained by the counselor is expressed as:

$$
\begin{gathered}
F=\alpha_{1} f_{1}+\alpha_{2} f_{2}+\alpha_{3} f_{3}=\alpha_{1}(2 d+e)+\alpha_{2}\left(h_{1}+l+\lambda_{1} j\right)+\alpha_{3}\left(s t+h_{1}+l+j\right) \\
\alpha_{1}, \alpha_{2}, \alpha_{3}>0, \alpha_{1}+\alpha_{2}+\alpha_{3}=1,0<d, e, t, h_{1}, l, j, s<1
\end{gathered}
$$

where, $F$ is the total income of the counselor, $f_{1}$ is the objective income, $f_{2}$ is the potential income, and $f_{3}$ is the future income; $d$ is the salary level, $e$ is the professional status outside, $h_{1}$ is the career planning level, $l$ is the self-improvement consciousness, $j$ is the degree of importance attached to counselors by colleges, $s$ is the counselor's working hours, and $t$ is the unit workload. The two influencing factors on the school's resource allocation of the counselor include the degree of importance attached to counselors by colleges and this counselor's performance ranking in the group. Therefore, $j$ was given a counselor performance ranking weight $\lambda_{1}$. To distinguish the effect of the three types of income on the total income $F$ of the counselor, $f_{1}, f_{2}, f_{3}$ were each given a weight $\alpha_{1}, \alpha_{2}, \alpha_{3}$, and the sum of $\alpha_{1}, \alpha_{2}, \alpha_{3}$ was 1 . Under the premise of the fixed workloads, the counselor's salary income, professional status, personal promotion, planning awareness, and the college's degree of attention are all elements to improve the counselor's income and can stimulate the counselor's work progress.

\subsection{Comprehensive profit and loss analysis}

As above, the counselor's profit and loss are expressed as:

$$
\begin{gathered}
M=F-G=2 \alpha_{1} d+\alpha_{2} e+\left(\alpha_{2}+\alpha_{3}\right) h_{1}-\left(\beta_{2}+\beta_{3}\right) h_{2}+\left(\alpha_{2}+\alpha_{3}+\beta_{1}\right) l \\
+\left(\alpha_{2} \lambda_{1}+\alpha_{3}\right) j+\left(\alpha_{3}-\beta_{1}\right) s t-\beta_{1} z-\beta_{2} c
\end{gathered}
$$

Thus, the influencing factors of the counselor's profit and loss are determined by the external salary level, professional status, work intensity, sudden situation, college's degree of attention, counselor's self-improvement level, and career planning degree. Among them, there are two decisive influencing factors: the work attitude of the counselor, i.e., active work or burnout; the management system of the college counselor, which depends on the college's degree of attention to the counselor.

\subsection{Participant analysis}

Based on the above, there are two main participants in the counselor's burnout phenomenon: the counselor and the college. Through the analysis for the comprehensive profit and loss, the logical mechanism for the burnout formation of the counselors and colleges is as follows:

1. The logic of counselor selection. When the counselor has a higher selfimprovement awareness and career planning direction, the improvement in work efficiency and the reduction in the work cost can create higher benefits for the college; at this time, $\lambda_{1}$ approaches 1 , indicating that the college tends to allocate more 
education resources to the counselor, and the college factor has a higher influence on the counselor's comprehensive profit and loss, which then reaches the highest. When the counselors feel burnout and do not have a sense of self-improvement and career planning, their work efficiency shall decrease, while the work cost shall increase, failing to provide sufficient efficiency for the college; at this time, $\lambda_{1}$ approaches 0 , indicating that the college has a small impact on the comprehensive benefit and lose value, and this value maintains in a relatively stable range.

2. The logic of college decision-making. Suppose that the college's degree of attention to counselors is between $0-1$, i.e. $0<\lambda_{1}<1$. When colleges attach more importance to counselors, the weight of $\left[\alpha_{2} \lambda_{1}+\alpha_{3}\right]$ becomes higher, and counselors can obtain a larger proportion of promotion space at low cost, so counselors are more willing to carry out self-promotion and career planning. otherwise, the weight of $\left[\alpha_{2} \lambda_{1}+\alpha_{3}\right]$ is lower, the cost required for counselors' promotion is higher, the counselors' self-improvement and career planning motivation are insufficient, and job burnout is prone to occur. Therefore, in addition to establishing a clear selfimprovement goal and career planning path, it's also most important for colleges to increase the treatment and attention of counselors for avoiding the job burnout.

Counselors pursue individual profits and losses, and colleges pursue collective profits and losses and self-development. Both parties tend to maximize their own interests. Therefore, there exist both a game and a compromise between the two. Theoretically, the counselors and the colleges do not know the decisions made by each other, i.e., the time for the counselors to obtain the system information is not fixed, and the colleges cannot know the working status of each counselor. However, under close contact, the two parties can vaguely perceive the other party's decision-making. In this case, the college's decision-making is prioritized, guiding the counselor to make the decision that the college expects.

\section{Model Analysis}

\subsection{Pure strategy}

The profit and loss of the counselors depends not only on their awareness-raising and planning skills, but also on the college's degree of attention to the counselor. Similarly, the profit and loss of the college depends not only on the number of resources it devotes to the counselor, but also on the counsel's work status and personal quality. For counselors, there are two options: burnout $a$ and active work $b$. For colleges, there are also two options: increase the degree of attention to the counselor $c$ and reduce the degree of attention to the counselor $d$. Then, the game model is established as follows:

The scenario that two parties make completely independent decisions Suppose colleges and counselors cannot predict each other's decisions, so the decisions of both parties are independent of each other. With the counselors' workload unchanged, when they choose a burnout and negative work style, the counselors can obtain basic 
ability enhancement $l$ and the cost $h$, and the college obtains basic work benefit $t$ and the basic improvement of the employee quality $l$. When they choose an active work style and attitude, the counselors can reap additional ability enhancement $l_{1}$ and work efficiency $t_{1}$ and reduce costs $h_{1}$, while colleges can also obtain additional employee work efficiency $t_{1}$ and employee quality improvement $l_{1}$. Based on the current system of colleges, if colleges put emphasis on the training of counselors, colleges will pay extra welfare costs and nurturing costs $w$, and increase employee work efficiency $t_{2}$ and employee quality $l_{2}$, while counselors will also gain additional ability enhancement $l_{2}$, work efficiency $t_{2}$ and cost reduction $h_{2} . l, l_{1}, l_{2}, t, t_{1}, t_{2}, h, h_{1}, w>0$. The game model between colleges and counselors is shown in Table 1 .

Table 1. Standard game model between colleges and counselors in their simultaneous decision-making

\begin{tabular}{|c|c|c|}
\hline & $\mathbf{A}$ & $\mathbf{B}$ \\
\hline \multirow{2}{*}{$C$} & $l+l_{2}+t_{2}-h+h_{2}$, & $l+l_{1}+l_{2}+t_{2}-h+h_{1}+h_{2}$, \\
& $t+t_{2}+l+l_{2}-w$ & $t+t_{1}+t_{2}+l+l_{1}+l_{2}-w$ \\
\hline \multirow{2}{*}{$D$} & $l-h$, & $l+l_{1}-h+h_{1}$, \\
& $t+l$ & $t+t_{1}+l+l_{1}$ \\
\hline
\end{tabular}

The above model did not constitute any Nash equilibrium. The counselor's is the dominant selection strategy. Regardless of colleges' selection, the counselor will always choose a positive work attitude. The selection strategy of colleges is to compare the expenditure of the cultivation system and the increase in employee efficiency, and then to make a decision. The more advanced the welfare system proposed by colleges, the greater the impact of the cultivation system on employee benefits, and the greater the tendency of colleges to attach importance; until $\left[t_{2}+l_{2}\right]$ is greater than $w$, colleges will choose the decision to "emphasize counselors".

But, if one more condition that college can establish an efficient training mechanism for counselors is added to make the employee ability enhancement $\left[t_{2}+l_{2}\right]$ be always greater than the expenditure $w$ of the welfare system, then there will be a Nash equilibrium $(C, B)$ in the game, that is, colleges attach importance to counselors and counselors are willing to improve themselves and work actively. In this case, the college and the counselor form a cooperative game. The gains of both parties increase, and the profit-loss difference are greater than zero, which is consistent with Pareto improvement.

The above shows the game of both parties in the non-contact mode. Regardless of whether colleges have advanced counselor welfare and training systems, counselors will remain in a positive working state in order to maximize work efficiency, while the colleges will tend to attach more importance to counselors under the condition of increasingly more efficient training policy of counselors (that is, the value of $\left[t_{2}+\right.$ $\left.l_{2}-w\right]$ gradually increases) in order to maximize the collective profit and loss.

The scenario that the college is the first mover in the decision-making In the implementation process of the college counselor management system in previous years, the college has released signals of whether to attach importance or not to the counselor, e.g., the welfare of the counselor in the past years, the implementation of the 
counselor project, the salary, and reward of the counselor, etc. On this basis, the counselors can construct a rough expectation of the attention degree of the college and speculate on the college's decision-making. Therefore, the game model in reality should undergo certain changes, i.e. the college is the first mover in the decisionmaking.

When colleges attach importance to counselors, counselors can obtain greater promotion space at low cost, and then they are more willing to carry out self-promotion and career planning, and to increase work costs $m$ for obtaining additional benefits $l_{3}$ (as a rational person, $l_{3}>m$ is inevitable). When colleges do not attach importance to counselors, counselors need to obtain promotion space at a high cost, and then their self-improvement and career planning motivation are insufficient, which is prone to job burnout and increases the psychological cost $m_{1}$.

Meanwhile, when colleges despise the counselors, the counselors will have a certain blame psychology for colleges, and job burnout will make the counselors receive a part of the psychological compensation, increasing the psychological gain $n$. In addition, most of the benefits are distributed according to the counselor's performance ranking. Due to the low performance caused by the counselor's burnout, the benefits received are minimal.

The reverse induction method found that a Nash equilibrium will be formed, that is, when colleges attach importance to counselors, counselors will work actively.

When colleges despise the counselor, there exist two situations: First, when the counselor's psychological quality is relatively fragile, $n$ caused by burnout and the psychological cost $m_{1}$ increase. Thus, the counselor tends to choose burnout work and form the second Nash equilibrium in the model. Second, when the counselor's psychological quality is strong, they can better cope with chronic stressors [7], $n$ caused by burnout and the psychological cost of work $m_{1}$ will decrease, forming another Nash equilibrium. However, both these two types of counselors exist in a college, and the two situations are likely to coexist, so the two equilibrium risks brought by the college's contempt are higher.

In order to avoid the risk of counselor's burnout to the greatest extent, and to achieve the state of maximizing benefits, colleges, as rational people, will tend to attach more importance to counselors, and counselors choose to work actively.

\subsection{Mixed strategy model}

Pure strategy equilibrium was introduced above. This section discusses the mixed strategy equilibrium. Suppose the probability that colleges attach importance to counselors is $\gamma$, and the probability that counselors work actively is $\theta$, the standard game formula is obtained, as shown in Table 2.

The gain functions of colleges and counselors are:

$$
\begin{gathered}
E(U)=(1-\theta) \gamma(t+l-w)+\theta \gamma\left(t+t_{1}+t_{2}+l+l_{1}+l_{2}-w\right)+(1-\theta)(1 \\
-\gamma)(t-l)+\theta(1-\gamma)\left(t+t_{1}+l+l_{1}\right) \\
=\gamma(2 l-w)+\theta \gamma\left(t_{2}+l_{2}\right)+(t-l)+\theta\left(t_{1}+l+l_{1}\right)
\end{gathered}
$$




$$
\begin{aligned}
E(T)=(1-\theta) & \gamma(l-h)+\theta \gamma\left(l+l_{1}+l_{2}+l_{3}+t_{2}-h+h_{1}+h_{2}-m\right)+(1 \\
& -\theta)(1-\gamma)(l-h+n)+\theta(1-\gamma)\left(l+l_{1}-h+h_{1}-m_{1}\right) \\
& =-\gamma n+\theta \gamma\left(l_{2}+l_{3}+t t_{2}+h_{2}+n-m+m_{1}\right)+(l-h+n) \\
& +\theta\left(l_{1}+h_{1}-m_{1}\right)
\end{aligned}
$$

It can be seen from the gain functions that college income is a linear function positively correlated with $\theta$. At the same time, the college income also depends on [2l$w]$; When the welfare system is more advanced, i.e., $[2 l-w]$ is greater than 0 , it means that the college attaches more importance to counselors, and the college's income is higher.

Table 2. The standard game form when colleges make their choice first

\begin{tabular}{|c|c|c|}
\hline & $\boldsymbol{A}(\mathbf{1}-\boldsymbol{\theta})$ & $\boldsymbol{B}(\boldsymbol{\theta})$ \\
\hline$C(\gamma)$ & $\begin{array}{c}l-h, \\
t+l-w\end{array}$ & $l+l_{1}+l_{2}+l_{3}+t_{2}-h+h_{1}+h_{2}-\mathrm{m}$, \\
$t+t_{1}+t_{2}+l+l_{1}+l_{2}-w$
\end{tabular}

The counselor's gain function is a linear function negatively correlated with $\gamma$, i.e., the stronger the counselor's overall mentality is, the smaller the absolute value of the slope of the $\gamma$ function and the greater the slope of the $\theta$ linear function.

The above analysis shows that the decision-making of both parties is related to each other and both affected by another external factor. The influencing factor in the decision-making of colleges is the implementation efficiency of the system. With the higher implementation efficiency, the colleges are more inclined to value the counselors. The influencing factor in the counselor's decision-making is the average mentality of the counselor group. The stronger the counselor's overall mentality and the greater the ability to withstand stress, the more inclined the counselor is to a proactive working attitude.

In summary, regardless of whether both parties know each other's decisions, the importance attached to counselors of colleges and the active work of counselors are the best strategies under this game model. That is, if colleges attach importance to the work of counselors and give counselors sufficient resources, motivation, and space, then the benefits of both parties will develop well.

\section{Evolutionary Game Model between Colleges}

\subsection{Model principle theory}

Evolutionary game theory negates the traditional theoretical basis-the assumption of rational people and uses dynamic analysis methods to examine the evolutionary trend of group behaviors by taking the limited rational participants as the research objects. During the game process, the participants can obtain decision information based on their own experience and the decisions of other participants, imitate good decisions, and eliminate bad decisions, so as to achieve the dynamic evolution of the 
group. This theory can be applied to analyze the influence process of a certain group on the whole group after selecting a better decision [9-11]. The group that has changed may be eliminated in the evolution process, or be integrated into and act on the large group. This study, mainly based on the evolutionary game model, discusses the influence of the improvement on all the colleges when a small number of colleges improve the counselor management system.

In terms of the counselors' treatment, it is assumed that a small number of colleges choose to improve the treatment of counselors, forming a group of strategy mutations, while other colleges still implement the original system. The replicator dynamic equation in evolutionary stable equilibrium is adopted:

Individuals in this group only choose one pure strategy at any time, and the strategy set is $S_{k}=\left\{s_{1}, s_{2}, \ldots, s_{k}\right\}$. At time $t$, the individual who chooses the strategy $s_{i} \in$ $S_{k}$ is $n_{i}(t)$, the total number of individuals in the group is $N$, and the state of the group at time $t$ is $x\left(x_{1}, x_{2}, \ldots, x_{k}\right)$, then the proportion of individuals who select the strategy $s_{i} \in S_{k}$ is $p_{i}(t)$ is given as:

$$
\begin{gathered}
p_{i}(t)=n_{i}(t) / N \\
0 \leq p_{i}(t) \leq 1, \quad \sum p_{i}(t)=1
\end{gathered}
$$

Let $f\left(s_{i}, x\right)$ be the expected payment of individuals in the group who choose the pure strategy $s_{i}$, and $f(x, x)=\sum x_{i} f\left(s_{i}, x\right)$ be the average expected payment of the group.

When the number of individuals in the group who choose a pure strategy $s_{i}$ grows to $f\left(s_{i}, x\right)$, the replicator dynamic equation can be derived as [8]:

$$
\frac{d x_{i}(t)}{d t}=x_{i}\left[f\left(s_{i}, x\right)-f(x, x)\right]
$$

\subsection{Simplified model building}

To simplify the model, it's assumed that only college 1 and college 2 participate in the game. A second-order symmetric game matrix was constructed, as shown in Table 3.

Table 3. 2-order symmetric game matrix

\begin{tabular}{|c|l|c|c|}
\hline \multicolumn{2}{|c|}{} & \multicolumn{2}{|c|}{ College 2 } \\
\cline { 3 - 4 } \multicolumn{2}{|c|}{} & Attach importance & Despise \\
\hline \multirow{2}{*}{ College 1} & Attach importance & $a-b, a-b$ & $a-b+\gamma d,-\gamma d-c$ \\
\cline { 2 - 4 } & Despise & $-\gamma d-c, a-b+\gamma d$ & $-c,-c$ \\
\hline
\end{tabular}

The following assumptions have been made:

Based on the profit and loss under the original system, if the two colleges choose the strategy of attaching importance to the counselor, then each college will receive an additional benefit $a$ and pay a cost $b$. If it chooses to maintain the original strategy, it will assume the risk cost $c$ caused by the counselor's burnout. 
If one college chooses attaching importance to the counselor and another college chooses to maintain the original system, then the counselor has a $\gamma$ chance to switch to the better college. The counselor's work benefit is $d$, thus, the college that adopts the strategy of attaching importance will obtain the income $\gamma d$ brought by this counselor, and encroached on the income $\gamma d$ of the other college under the original system.

\subsection{Analysis of replicator dynamics and stability}

Assuming that the proportion of colleges in the group that chooses to value counselors is $r$, then the proportion of colleges that choose to maintain the status quo (despising the counselors) is $(1-r)$, and the expected benefits of both parties are as follows:

$$
\begin{gathered}
f_{1}=(a-b) r+(a-b+\gamma d)(1-r) \\
f_{2}=(-\gamma d-c) r-c(1-r)
\end{gathered}
$$

The above $f_{1}$ is the profit and loss of the college that attaches importance to the counselor, and $f_{2}$ is that of college that is maintained as the status quo.

The average expected profit and loss of the college group is:

$$
f_{0}=f_{1} r+f_{2}(1-r)=2 c r^{2}+(a-b+c) r-c
$$

when $f_{1}$ and $f_{2}$ are not equal, the player with lower profit and loss will abandon the original strategy and choose a better strategy. At this time, the proportion of colleges $r$ that choose to maintain the original system no longer be a fixed state. According to the above formula, the duplicator dynamic equation is derived as:

$$
F(r)=\frac{d r}{d t}=r\left(f_{1}-f_{0}\right)=r(1-r)\left(f_{1}-f_{2}\right)=r(1-r)(a-b+c+\gamma d)
$$

Let the right side of the above formula be 0 , two stationary solutions to the equation can be obtained:

$$
r_{1}=0, r_{2}=1
$$

According to the evolutionary stability strategy, the group will eventually stay on a comparative advantage strategy over time, and the system can resist small external shocks within the evolutionary stable and balanced attraction domain. When some individuals deviate from the scope, the replicator dynamics can help it gradually return to the original stable point, that is, $F^{\prime}(r)=\frac{d F(r)}{d t}<0$.

Using linear stability, determine the stability of two stationary solutions:

1. At the stationary solution $r_{1}=0$, the linear equation can be obtained as follows:

$$
F^{\prime}(0)=\left.\frac{d F(r)}{d t}\right|_{r=0}=a-b+c+\gamma d
$$


Since $a, b, c, d, \gamma$ are all normal values, and the benefit $a$ is often greater than the $\operatorname{cost} b$, then $F^{\prime}(0)>0$, and the steady-state solution $r_{1}$ is unstable.

2. At the stationary solution $r_{2}=1$, the linear equation can be obtained as follows:

$$
F^{\prime}(1)=\left.\frac{d F(r)}{d t}\right|_{r=1}=-a+b-c-\gamma d
$$

Since $a, b, c, d, \gamma$ are all normal values, and the benefit $a$ is often greater than the cost $b$, then $F^{\prime}(1)<0$, and the steady-state solution $r_{1}$ is stable.

\subsection{Discussion on stable equilibrium solutions}

The analysis found that there is a stable equilibrium solution for the duplicator dynamic equation of this college group, that is, $r_{2}=1$. When $a, b, c, d, \gamma$ are all normal values, and the benefit $a$ is often greater than the cost $b$ (college's counselor management system is more efficient), the college that chooses to change the original system can obtain a positive benefit and eliminate the tendency of job burnout, and then evolve stably.

This means that under the problem of counselor burnout, the entire college system remains unbalanced until the management system of counselors in all colleges has changed. This is because the changes in the counselor management system of colleges can effectively reduce the risk cost of counselor burnout and also obtain additional benefits.

When a part of colleges attaches more importance to counselors, it will bring various pressures to other colleges:

1. The pressure of counselors' burnout. Under the original system, the counselors can find that the cost of active work is higher, but the benefits are lower. Plus the unclear promotion space and confused career development, they gradually form a psychological state of the burnout, which greatly reduce their work efficiency and enthusiasm.

2. The pressure of counselors to change jobs. In addition to job burnout caused by the original system, the treatment of counselors is also worse. Under the dual effect of burnout psychology and treatment difference, they are likely to choose to job-hop and find colleges of the same status with more promotion space and better treatment, which can lead to the brain drain of colleges.

3 . The pressure of college reputation. For colleges that pay more attention to counselors, the counselors have higher enthusiasm and effectiveness, helping to form a better image of colleges and bring a reputation that is far superior to other colleges, thereby causing public pressure in the college circle.

As above, the behavior of some colleges to change the management system of counselors will cause other colleges to imitate until all colleges make changes. Such a result can effectively improve the burnout psychology of college counselors and form a better faculty style. 


\section{Conclusion}

First, the occurrence of the counselor's burnout depends on the difference between the cost and benefit of the work. The main influencing factors of the counselor's burnout include job treatment, career achievement, self-improvement level, and career planning degree, etc. The growth of the counselor's burnout varies with the level of the mentality and the importance of the college to the counselor. Therefore, to effectively avoid the occurrence of the counselor's burnout, the counselors should exercise their mind, to be not easily interfered with by the external environment. Colleges should establish more efficient and perfect counselor incentive system and career development system, and pay more attention to the role and development of counselors in the college education system.

Second, it is the rational choice of both parties that colleges choose to reform the counselors' management system and counselors choose to work actively to avoid job burnout. Based on the current weak counselor system, when a small number of colleges choose to innovate the counselor management system and improve the counselor's treatment, other colleges will also imitate until all colleges and universities have completed the system reform, which further promotes the establishment and improvement of the college education system.

Based on the above conclusions, the authors believe that: to prevent the burnout of counselors, it's necessary to mainly start from college decision-making, improve the treatment of counselors, establish a comprehensive counselor training system and reward and punishment system, improve the career development and promotion path of counselors, and reduce the gap between the counselors and professional teachers. Meanwhile, supports should be also provided to guide the counselor's development pursuit and career concept, strengthen their mental health training, avoid the many negative damages caused by the job burnout, and form a good professional style for college counselors.

\section{Acknowledgement}

The research is supported by the Social Science Research Foundation in Higher Education of Hebei Province of China in 2019 (Grant number: SZ19065); the Student Work and Party Construction Project of Northeastern University at Qinhuangdao in 2020 (Grant number: 005)

\section{$7 \quad$ References}

[1] Freudenberger, H. J. (1975). The staff burn-out syndrome in alternative institutions. Psychotherapy: Theory, Research \& Practice, 12(1): 73-82. https://doi.org/10.1037/h00864 $\underline{11}$

[2] Leiter, M. P., Maslach, C., Frame, K. (2014). Burnout. The encyclopedia of clinical psychology, 1-7. https://doi.org/10.1002/9781118625392.wbecp142 
[3] Byrne, B. M. (1994). Burnout: Testing for the validity, replication, and invariance of causal structure across elementary, intermediate, and secondary teachers. American Educational Research Journal, 31(3): 645-673. https://doi.org/10.3102/0002831203100 $\underline{3645}$

[4] Burke, R. J., Greenglass, E. R. (2001). Hospital restructuring, work-family conflict and psychological burnout among nursing staff. Psychology \& health, 16(5): 583-594. https:// doi.org/10.1080/08870440108405528

[5] Piedmont, R. L. (1993). A longitudinal analysis of burnout in the health care setting: The role of personal dispositions. Journal of personality assessment, 61(3): 457-473. https://doi. org/10.1207/s15327752jpa6103 3

[6] Smolentseva, A. (2017). Universal higher education and positional advantage: Soviet legacies and neoliberal transformations in Russia. Higher education, 73(2): 209-226. https ://doi.org/10.1007/s10734-016-0009-9

[7] Jenkins, S. R., Maslach, C. (1994). Psychological health and involvement in interpersonally demanding occupations: A longitudinal perspective. Journal of Organizational Behavior, 15(2): 101-127. https://doi.org/10.1002/job.4030150202

[8] Gintis, H. (2000). Game theory evolving: A problem-centered introduction to modeling strategic behavior. Princeton university press. https://doi.org/10.2458/v7i1.21553

[9] Swinkels, J. M. (1992). Evolutionary stability with equilibrium entrants. Journal of Economic Theory, 57(2): 306-332. https://doi.org/10.1016/0022-0531(92)90038-J

[10] Aboelazm, Y.M., Wahba, W.E., Moustafa Hassan, M.A. (2018). Mitigation of voltage swells in IEEE 30 bus and IEEE 57 bus systems using evolutionary techniques. European Journal of Electrical Engineering, 20(4), 499-516. https://doi.org/10.3166/EJEE.20.499$\underline{516}$

[11] Song, Y., Cao, Y.P. (2019). VMI \& TPL supply chain coordination based on evolutionary game. Journal Européen des Systèmes Automatisés, 52(2), 215-2222. https://doi.org/10.1 $\underline{8280 / j e s a .520215}$

\section{Authors}

Xiaolei Wang was born in Jilin Province, China in 1985. She received bachelor degree in economics from Jilin University in 2007, and received master degree in economics from Jilin University in 2011. Now she is a lecturer working at School of Control Engineering of Northeastern University at Qinhuangdao. She is the author of several educational papers. Her main research area is higher education.

Ruoxuan Zhang was born in Zhejiang Province, China in 2000. Since 2018, she has studied finance at Northeastern University Qinhuangdao as an undergraduate. Her research interests include related applications of game theory, finance and economics.

Zengxin Li was born in Henan Province, China in 1981. She received her B.S. degree in economics in 2003 and M.S. degree in Management in 2009, from Northeastern University. She is working in Department of Economics at Qinhuangdao Vocational and Technical College as Associate Professor. Her research areas of interest are business management and teaching reform of higher education. 
Junlong Chen was born in Shandong Province, China in 1984. He studied at Jilin University from 2004 to 2013, and received bachelor, master and doctor degrees in economics. He is an associate professor in the School of Economics of Northeastern University at Qinhuangdao. He is the author of four books, and more than 60 academic papers. His main research interest includes public policy and higher education.

Article submitted 2020-07-03. Resubmitted 2020-08-07. Final acceptance 2020-08-07. Final version published as submitted by the authors. 